AperTO - Archivio Istituzionale Open Access dell'Università di Torino

Editorial for the special issue on "Metabolic engineering"

This is a pre print version of the following article:

Original Citation:

Availability:

This version is available http://hdl.handle.net/2318/1737281

since 2020-04-25T09:25:59Z

Published version:

DOI:10.1002/bab.1904

Terms of use:

Open Access

Anyone can freely access the full text of works made available as "Open Access". Works made available under a Creative Commons license can be used according to the terms and conditions of said license. Use of all other works requires consent of the right holder (author or publisher) if not exempted from copyright protection by the applicable law. 


\title{
Editorial for the special issue on "Metabolic engineering"
}

\author{
Roberto Mazzoli ${ }^{1}$, Cheng Guang Liu $^{2}$
}

${ }^{1}$ Structural and Functional Biochemistry. Laboratory of Proteomics and Metabolic Engineering of Prokaryotes. Department of Life Sciences and Systems Biology. University of Torino. Via Accademia Albertina 13. 10123 Torino. Italy.

${ }^{2}$ State Key Laboratory of Microbial Metabolism, Joint International Research Laboratory of Metabolic \& Developmental Sciences, School of Life Sciences and Biotechnology, Shanghai Jiao Tong University, Shanghai 200240, China.

Metabolic engineering is the science of targeted manipulation of cellular metabolism through modification/inactivation of specific biochemical reactions and/or introduction of new ones that is generally obtained by means of recombinant DNA technology. As a rapidly expanding discipline, metabolic engineering has established a broad range of applications that includes the medical area (e.g. for the analysis of the metabolism of tissues and organs and the identification of targets for diseases), the environmental field (e.g. in pollutant bioremediation), and the development of cell factories. The latter includes the: i) extension of the range of substrates; ii) increased production of desired chemicals; iii) biosynthesis of novel compounds; iv) improvement of cellular properties (such as the tolerance to stressful industrial conditions).

This special issue provides a glimpse on the richness and diversity of applications of metabolic engineering in the health/medical, bioremediation and biorefinery fields. Improved production of molecules with pharmaceutical and/or nutraceutical application has been reported by Niu et al. (Niu et al., 2019) and Karuppaiya and Tsay (Karuppaiya \& Tsay, 2019). Niu et al. (Niu et al., 2019) undertook a coordinated improvement of both carbon and nitrogen metabolism of Bacillus subtilis to increase production of $\mathrm{N}$-acetylglucosamine, a compound for arthritis treatment. Karuppaiya and 
Tsay (Karuppaiya \& Tsay, 2019) introduced a biotechnological approach to that represents a promising alternative for producing secondary plant metabolites with recognized pharmaceutical properties (e.g. anticancer) thus avoiding extinction of threatened traditional medicinal plants. Saba et al. (Saba et al., 2020) reported an interesting example of cloning of the gene encoding a microbial antigen, i.e. the $6 \mathrm{kDa}$ early secretory antigenic target (ESAT-6) of Mycobacterium tuberculosis, in an edible plant (i.e. Brassica oleracea, broccoli) for developing an oral vaccine against tuberculosis. The review by Yadav and Shukla (Yadav \& Shukla, 2019) deals with the growing interest for the effect of gut microbiota on human health and, more specifically, describes opportunities to exploit genetic techniques to engineering designer probiotics to target specific diseases. Bioremediation is the use of enzymes and microorganisms for degradation of environmental pollutants-.. In this field, metabolic engineering has been a effered the-tools to develop improved strains able to degrade the most persistent pollutants by tailoring their metabolic pathways as described by Huang and Lin (Huang \& Lin, 2019).

Biorefinery intends the production of industrially relevant compounds through biomass bioconversion, thus replacing traditional less eco-friendly processes such as oil refinery. The contributions included in the current special issue focus on different challenges that development of efficient biorefining processes should face. The paper by Sakdaronnarong et al. (Sakdaronnarong et al., 2019) reminds us the importance of the characteristics (e.g. sugar content, recalcitrance) of the biomass used as feedstock for the efficiency of $1^{\text {st }}$ and $2^{\text {nd }}$ generation biorefinery processes. Mazzoli (Mazzoli, 2019) has reviews-reviewed the opportunities and challenges of metabolic engineering strategies aimed at direct fermentation of lignocellulose to lactic acid, a compound with several applications including the synthesis of biodegradable plastics. Saturation of protein secretion pathways and accumulation of unfolded proteins by expression of heterologous cellulases is certainly among the main hurdles of research aimed at engineering cellulolytic ability in industrial producers such as Saccharomyces cerevisiae. The system developed by Cedras et al. (Cedras, Kroukamp, Van Zyl, \& Den Haan, 2019) benefits the selection of candidate cellulases with reduced induction of the 
unfolded protein response. The $3^{\text {rd }}$ generation biorefinery, based on microalgae, is the focus of three reviews in this special issue. Microalgae are alternative attractive platforms for the production of high-value compounds such as biofuels, enzymes, therapeutic proteins, hormones, vaccines and vitamins, but their utilization suffers from poor biomass and product yields, and expensive downstream processing. Shahid et al. (Shahid et al., 2019) summarized state-of-the-art knowledge on lipid biosynthetic pathways and metabolic engineering strategies aimed at lipid accumulation in microalgae for exploitation in biodiesel production. Siddiqui et al. (Siddiqui et al., 2019) have explored the potential and advantages of engineering the genome of microalgae chloroplast instead of their nuclear genome for biotechnological purposes. Induction of self-flocculation by genetic engineering seems a promising strategy to improve microalgal biomass harvesting, as suggested by Malik et al. (Malik et al., 2019).

Engineering microorganisms for improved production of high-value chemicals (e.g. solvents) often requires engineered strains more tolerant to the compound of interest. Furthermore, microorganisms in industrial fermentation are exposed to various harsh conditions such as high temperature, high osmolarity or very acid or alkaline pH. Lv et al. (Lv et al., 2019) discuss the-strategies, including rational and evolutionary pathway engineering, for developing strains with increasedhigh tolerance to industrial environments.

Rapid expansion of metabolic engineering is supported by continuous evolution of techniques for studying metabolic pathways, such as analysis of metabolic flux and omics (e.g. transcriptomics, proteomics, metabolomics), thus allowing the identification of metabolic nodes to regulate metabolic reactions by metabolic engineering strategies and innovative tools. Zhang and Lin (Zhang \& Lin, 2019) applied metabolic flux analysis to implement the mathematical model of Saccharomyces cerevisiae metabolism so as to better describe growth under redox potential-controlled during veryhigh-gravity ethanol production, which are more relevant to industrial ethanol fermentation. -Yang et al. (Yang et al., 2019) exemplifies that the omics datasets could be a convenient approach to discover 
new regulatory elements (e.g. ethanol-inducible gene promoters). Although most metabolic engineering studies have relied too much upon "traditional" gene manipulation, e.g. gene deletion, sophisticated tools such as Clustered Regularly Interspaced Short Palindromic Repeats -interference (CRISPRi) has been recently used as a more tunable strategy to repress gene expression as described by Schultenkämper et al. (Schultenkämper, Brito, \& Wendisch, 2020).

A farther step towards “unconventional” metabolic engineering is presented by Ge and Xu (Ge \& Xu, 2019) based on the cell-free protein synthesis. Cell-free metabolic engineering offers a number of advantages over traditional metabolic engineering such as the production of compounds which are toxic for cells and prevention of byproduct biosynthesis (by excluding unnecessary pathways) but requires optimization. Their investigation targets the macromolecular crowding effect on the efficiency of in vitro biochemical reactions.

\section{References}

Cedras, G., Kroukamp, H., Van Zyl, W. H., \& Den Haan, R. (2019). The in vivo detection and measurement of the unfolded protein response in recombinant cellulase producing Saccharomyces cerevisiae strains. Biotechnology and Applied Biochemistry. https://doi.org/10.1002/bab.1819

Dvořák, P., Nikel, P. I., Damborský, J., \& de Lorenzo, V. (2017). Bioremediation 3.0: Engineering pollutant-removing bacteria in the times of systemic biology. Biotechnology Advances, Vol. 35, pp. 845-866. https://doi.org/10.1016/j.biotechadv.2017.08.001

Ge, X., \& Xu, J. (2019). Macromolecular crowding effects on transcription and translation are regulated by free magnesium ion. Biotechnology and Applied Biochemistry. https://doi.org/10.1002/bab.1827

Himmel, M. E., Ding, S. Y., Johnson, D. K., Adney, W. S., Nimlos, M. R., Brady, J. W., \& Foust, 
T. D. (2007). Biomass recalcitrance: Engineering plants and enzymes for biofuels production. Science, Vol. 315, pp. 804-807. https://doi.org/10.1126/science.1137016

Huang, X., \& Lin, Y. (2019). Reconstruction and analysis of a three-compartment genome-scale metabolic model for Pseudomonas fluorescens . Biotechnology and Applied Biochemistry. https://doi.org/10.1002/bab.1852

Karuppaiya, P., \& Tsay, H. S. (2019). Enhanced production of podophyllotoxin, kaempferol, and quercetin from callus culture of Dysosma pleiantha (Hance) Woodson: An endangered medicinal plant. Biotechnology and Applied Biochemistry. https://doi.org/10.1002/bab.1810

Lv, Z., Zhou, J., Zhang, Y., Zhou, X., Xu, N., Xin, F., ... Dong, W. (2019). Techniques for enhancing the tolerance of industrial microbes to abiotic stresses: A review. Biotechnology and Applied Biochemistry. https://doi.org/10.1002/bab.1794

Malik, S., Khan, F., Atta, Z., Habib, N., Haider, M. N., Wang, N., ... Zhu, H. (2019). Microalgal flocculation: Global research progress and prospects for algal biorefinery. Biotechnology and Applied Biochemistry. https://doi.org/10.1002/bab.1828

Mazzoli, R. (2019). Metabolic engineering strategies for consolidated production of lactic acid from lignocellulosic biomass. Biotechnology and Applied Biochemistry, doi: 10.1002/bab.1869.

Niu, T., Lv, X., Liu, Z., Li, J., Du, G., \& Liu, L. (2019). Synergetic engineering of central carbon and nitrogen metabolism for the production of $\mathrm{N}$-acetylglucosamine in Bacillus subtilis. Biotechnology and Applied Biochemistry. https://doi.org/10.1002/bab.1845

Saba, K., Sameeullah, M., Asghar, A., Gottschamel, J., Latif, S., Lössl, A. G., ... Waheed, M. T. (2020). Expression of ESAT-6 antigen from Mycobacterium tuberculosis in broccoli: An edible plant. Biotechnology and Applied Biochemistry. https://doi.org/10.1002/bab.1867

Sakdaronnarong, C., Sraphet, S., Srisawad, N., Chantasod, R., Jonglertjunya, W., \& Triwitayakorn, K. (2019). Rheological characteristics and genotype correlation of cassava root for very high 
gravity ethanol production: The influence of cassava varieties and harvest times. Biotechnology and Applied Biochemistry. https://doi.org/10.1002/bab.1818

Schultenkämper, K., Brito, L. F., \& Wendisch, V. F. (2020). Impact of CRISPR interference on strain development in biotechnology. Biotechnology and Appllied Biochemistry, https://doi.org/10.1002/bab.1901.

Shahid, A., Rehman, A. ur, Usman, M., Ashraf, M. U. F., Javed, M. R., Khan, A. Z., ... Mehmood, M. A. (2019). Engineering the metabolic pathways of lipid biosynthesis to develop robust microalgal strains for biodiesel production. Biotechnology and Applied Biochemistry. https://doi.org/10.1002/bab.1812

Siddiqui, A., Wei, Z., Boehm, M., \& Ahmad, N. (2019). Engineering microalgae through chloroplast transformation to produce high-value industrial products. Biotechnology and Applied Biochemistry. https://doi.org/10.1002/bab.1823

Yadav, M., \& Shukla, P. (2019). Efficient engineered probiotics using synthetic biology approaches: A review. Biotechnology and Applied Biochemistry. https://doi.org/10.1002/bab.1822

Yang, Y., Rong, Z., Song, H., Yang, X., Li, M., \& Yang, S. (2019). Identification and characterization of ethanol-inducible promoters of Zymomonas mobilis based on omics data and dual reporter-gene system. Biotechnology and Applied Biochemistry. https://doi.org/10.1002/bab.1838

Zhang, Y., \& Lin, Y. (2019). Metabolic flux analysis of Saccharomyces cerevisiae during redox potential-controlled very-high-gravity ethanol fermentation . Biotechnology and Applied Biochemistry. https://doi.org/10.1002/bab.1861 